\title{
Familial Breast and Bowel Cancer: Does It Exist?
}

\author{
Rodney J. Scott, Katie A. Ashton \\ Discipline of Medical Genetics, School of Biomedical Sciences, Faculty of Health, University of Newcastle and Hunter Medical Research Institute, Newcastle, Australia
}

Key words: breast cancer, colorectal cancer, HNPCC, disease risk

Corresponding author: Rodney J. Scott, Discipline of Medical Genetics, School of Biomedical Sciences, Faculty of Health, University of Newcastle, Callaghan, NSW 2308, Australia. Phone +61 24921 4974, fax +61 249214253 , e-mail: Rodney.Scott@hunter.health.nsw.gov.au

Submitted: 18 February 2004

Accepted: 27 February 2004

\begin{abstract}
There is much debate in the literature about familial predispositions to breast and bowel cancers yet little evidence is forthcoming to suggest that there are susceptibility genes that can account for such kindreds. Within the context of known susceptibility genes the most controversial syndrome is hereditary non-polyposis colorectal cancer (HNPCC). In HNPCC, breast cancers do occur yet their incidence overall is no different to that of the general population yet when studied at the molecular level these tumours often display DNA microsatellite instability suggesting that they do indeed belong to this genetic entity. In this review we examine the relationship between breast and bowel cancer and suggest a possible explanation for the diverse points of view described in the literature.
\end{abstract}

\section{Introduction}

Knowledge about the genetics of inherited predispositions to cancer has increased significantly over the last ten years yet there remain many unresolved issues. The identification of the genetic basis of familial breast cancer and familial forms of bowel cancer has resulted in the development of much improved screening strategies for disease prevention and has altered our awareness to disease susceptibility. Notwithstanding, only a very small proportion of bowel and breast cancers are attributed to the inheritance of a predisposing gene (approximately 2-7\% and 5\%, respectively) [1-5]. The discovery of many more cancer susceptibility genes continues. Rapid technological advances are aiding the cancer detection process, which will ultimately lead to improved prevention of familial bowel and breast cancer.
Both bowel and breast cancers are prevalent among the population and current investigations aim to identify additional genes that contribute to these genetic predispositions. Familial breast cancer and familial bowel cancer outside of the context of known genetic predispositions to disease (Peutz-Jeghers syndrome (PJS), hereditary non-polyposis colorectal cancer (HNPCC) or hereditary breast and/or ovarian cancer or $\mathrm{HBOC}$ ) indicate that there is an overlap between the two predispositions within families. Based on current information sourced from the literature, little is known about the exact genetic relationship between bowel and breast cancer risk. Before examining the evidence for a breast/bowel cancer susceptibility gene the relationship between the two malignancies should be assessed within the context of known genetic predispositions to disease.

The main issues are sample populations, age of onset, differences between men and women, 
microsatellite instability, cancer susceptibility genes and the pathways that they encode. The purpose of this review is to illustrate what is known about the association between bowel and breast cancer and the evidence for and against this notion.

\section{Breast and bowel cancer risk in inherited cancer syndromes}

The first investigations into HNPCC and breast cancer were conducted by Watson and Lynch [6] in 1993, who showed that HNPCC patients have no increased risk of developing breast cancer. Current research however has identified the possibility that individuals with HNPCC are predisposed to developing breast cancer [7-9]. Studies examining the relationship between bowel and breast cancer in HNPCC often conflict with each other due to the populations investigated and the analysis performed.

HNPCC is an autosomal dominant disease $[4,10$, 11], the aetiology of which emerged from many avenues that included linkage analysis, segregation studies and molecular genetic analyses [12].

The genetic basis of HNPCC is, at least in part, due to mutations in genes encoding proteins involved in the DNA mismatch repair (MMR) pathway. The most common mutations are found in the mutt homolog 1 (hMLH1) and mutS homolog 2 (hMSH2) MMR genes $[4,10,11,13]$. The available evidence suggests that there is a direct association between MMR mutations and HNPCC and that hMSH2 and hMLH1 account for up to $60 \%$ of all families that adhere to the Amsterdam criteria and about $30 \%$ if the Bethesda criteria are used [4, 10-13]. The mutS homolog 6 (hMSH6) and postmeiotic segregation 2 (hPMS2) genes account for only a small proportion of HNPCC families, probably less than 5\% [14]. Currently over 200 allelic variants in $\mathrm{hMSH} 2$ and hMLH1 have been linked with HNPCC [12]. Mutations in DNA MMR genes result in a characteristic tumour signature known as microsatellite instability (MSI), which can be used to aid in the diagnosis of HNPCC.

Like HNPCC, breast cancer development can occur due to certain defective genes associated with the maintenance of genomic integrity. Two intensely studied genes are breast cancer gene 1 (BRCA1) and breast cancer gene 2 (BRCA2). Both BRCA1 and BRCA2 appear to be linked to the recognition of DNA double strand breaks and double strand break repair [15]. Genetic modeling studies, however, indicate that other genes exist that predispose to breast cancer [16]. Mutations in BRCA1 account for more than $50 \%$ of cases of breast cancer within a family of at least four affecteds diagnosed under the age of 60 . Carriers of BRCA1 mutations have an $85 \%$ likelihood of developing breast cancer by the age of 80 . BRCA2 accounts for approximately $30 \%$ of breast cancer families where there are four or more cases also diagnosed under the age of 60 . Similar to BRCA1, carriers of BRCA2 mutations have an $85 \%$ probability of developing breast cancer by the age of 80 [3]. The disease spectrum observed in BRCA 1 families appears to be very restricted whereas BRCA2 appears to be associated with a more pleiotropic disease phenotype (see this issue of the journal for a review of BRCA1 and BRCA2 function).

Within the context of $\mathrm{HBOC}$ families there appears to be no relationship between breast and bowel cancer although initially it was believed that mutations in BRCA1 conferred an increased relative risk of bowel cancer [17]. On re-examination with larger numbers of families this relationship has since been shown not to exist [18]. There is no evidence to suggest that mutations in BRCA2 confer any increased risk of bowel cancer. Together, it appears that $\mathrm{HBOC}$ families do not have any increased risk of bowel cancer development [18] which is in contrast to HNPCC families where the epidemiological evidence remains inconclusive.

\section{Breast cancer and HNPCC}

Mutations in DNA MMR genes appear to be associated with an increased probability of epithelial tumours, most notably bowel and endometrial cancers. Additional to this are a variety of other less frequent malignancies that have been noted to be over-represented in HNPCC families and these include cancers of the ureter, gall bladder, pancreas and nasopharyngeal tumours. The notable exception is breast cancer although it has been reported to be present in HNPCC families. Since the identification of DNA MMR genes and their association with HNPCC there have been anecdotal reports of breast cancers occurring in families that have been genetically characterised. Small studies assessing the presence of DNA microsatellite instability (MSI) revealed its presence in breast tumours derived from patients who harboured germline MMR gene mutations suggesting by association that breast tumours do occur as an entity within the context of HNPCC [7-9]. When, however, the incidence of breast tumours is examined in families that adhere to either the Amsterdam or Bethesda criteria no obvious statistically significant result can be observed between them and the general population. 
Scott et al (2001) subdivided HNPCC families into three groups, those that harboured hMSH2 mutations, $\mathrm{hMLH1}$ mutations and mutation negative kindreds. The standard incidence rate was determined and the $\mathrm{hMLH} 1$ group displayed a small but significantly greater incidence in breast cancer compared to the general population. The result was unexpected but when compared to the standard incidence rates of bowel cancer and a number of other cancers it appeared to be low. If all families were considered together the incidence rate difference disappeared [10]. The results of this study provided some evidence for breast cancer to be considered part of the entity of HNPCC.

Vasen et al (2001) provide some evidence that breast tumours within HNPCC families present at an earlier age than expected. They propose that MMR gene mutation carriers are likely to have accelerated tumour development which will be observed as early onset breast cancer [19].

\section{Microsatellite instability (MSI) and HNPCC}

MSI studies have primarily focused on bowel cancer rather than breast cancer and this potentially may confound the interpretation of results. The DNA microsatellite markers chosen by the International Collaborative Group for HNPCC was directed towards the identification of MSI in colorectal cancers rather than in other cancers $[12,19]$. The microsatellite markers used to assess MSI were chosen because of their relationship to known genetic factors associated with bowel cancer development and they include D5S534 (linked to the APC gene), D2S123 (linked to hMSH2), D17S250 (linked to TP53), Bat 26 (linked to a poly (A) tract in exon 5 of $\mathrm{MSH} 2$ ) and Bat 25 (linked to a poly (A) tract in c kit). When these markers are used to assess bowel tumours derived from patients from HNPCC families approximately $90 \%$ will display MSI. In contrast, breast cancers derived from HNPCC patients show a low rate of MSI and thereby contributing to the difficulty in determining whether an association between bowel and breast cancer exists [4, 13, 19-21]. There has been no systematic analysis of genes associated with MMR in MSI negative patients even though there are examples of mutations being found in MSI negative tumours [12]. Liu et al (2000) for example, showed MSI positive tumours in 16 out of possible 22 HNPCC patients, and they identified a DNA MMR causative mutation in 1 of $37 \mathrm{MSI}$ negative tumours [22]. Risinger et al (1996) demonstrated that MSI is much more common in breast cancers from HNPCC families than in their sporadic counterparts [9].

Risinger et al (1996), de Leeuw et al (2002), and Boyd et al (1999) all demonstrate MSI in both breast cancer tissue and bowel tumours harbouring hMLHI mutations [7-9] and Vasen et al (2001) showed one patient that exhibited MSI in a breast cancer tumour. In contrast, Caluseriu et al (2001), and Muller et al (2002) did not find MSI within the breast cancers they investigated [4, 13]. Together, this information suggests that MSI should not be the only technique used to determine whether there is a bowel and breast cancer association within the context of HNPCC. Mutational analysis of the MMR genes should be performed. Mitchell et al (2002) state that mutations that are evident within MSI negative patients may show that mutations in MMR genes do not always show MSI but confer the mechanisms of tumorigenesis [12].

\section{Sample populations}

The incidence rates of HNPCC vary globally and they appear higher of developed countries. This difference may be due to ethnicity and environmental factors such as lifestyle and diet [12]. Scott et al (2001) reported in an Australian population, a higher incidence of breast cancer in individuals with hMLH 1 mutations and mutation negative patients compared to patients with hMSH2 mutations [10]. Vasen et al (2001) presented results from the Dutch population showing no association between both cancers. In reply to Vasen et al, Scott suggests that Dutch and Australian populations differ in their HNPCC and breast cancer incidences since $\mathrm{hMLH} 1$ mutations are more common in the Australians. Scott concludes by agreeing that breast cancer may present at an earlier age due to MMR defective genes [19].

Vasen et al published data that indicates that there is no association between bowel and breast cancer in the Dutch population since only seven of 328 patients exhibited mutations in $\mathrm{hMLH} 1$ and $\mathrm{hMSH} 2$ combined. However, they state that the MMR pathway may lead to more rapid tumour development thereby accounting for the recognition of early onset breast cancer development [19].

Other studies examining the relationship between breast and bowel cancer have only used small populations of breast and bowel cancer patients. For example, Borg et al (2000) discovered both a BRCA1 mutation and an $\mathrm{hMLH} 1$ mutation in the same individual. They suggest from this finding that BRCAl and hMLHI mutations have a synergistic effect with respect to the development of bowel and breast cancer [1 1]. To confirm the existence of a relationship between breast and bowel cancer in the context of HNPCC, much larger sample populations must be studied to provide statistical rigour. 


\section{Males vs. females}

Within the HNPCC population, males are more likely to suffer from colorectal cancer than females. As age increases within both sexes, HNPCC risk increases. Male mutation carriers have almost twice the probability (80\%) of developing colorectal cancer than females (40\%) by the age of 70 . This difference in penetrance between the sexes is not understood, but may be due to hormonal differences, the presence of a genetic modifier or an $X$ linked gene that confers some protection against colorectal disease [12]. Boyd et al. (1999) identified malignancies within the breast and colon of a male within HNPCC kindred. The male had an hMLH1 mutation, which segregated within the kindred. They suggest that breast cancer can occur as an integral tumour in HNPCC [7]. Cancer of the breast in males is rare and accounts for approximately $0.5 \%$ of all breast cancers in the US [7]. Further research may demonstrate the slight differences in genetics of male and female breast carcinomas in HNPCC families [1 1].

\section{Proposition}

We propose a possible explanation for the increased risk of breast cancer seen within HNPCC individuals. The relative age of onset of breast cancer within individuals with both breast and bowel cancer is younger at approximately 40 to 50 years of age compared to the general population where disease peaks between 65 and 70 years of age. If germline changes in the MMR genes accelerate disease development then it is to be expected that disease initiation may occur at much earlier stages and what is being observed in HNPCC is merely a reflection of the population incidence of the disease, which occurs approximately 20 years earlier than expected. The evidence for this notion is circumstantial and is related to the clonal expansion of the breast at puberty and during pregnancy [23]. If an event occurs during puberty that results in a somatic mutation in a gene that alters breast cancer risk on a background of MMR deficiency then it is to be expected that disease development will ensue.

\section{Future}

The association of breast cancer with HNPCC remains controversial but clues are beginning to emerge that may solve this riddle once and for all. Recently, the CHEK2 gene has been identified as a cofactor in breast cancer risk. CHEK2 is a key mediator in DNA damage response pathways. It is a G2 checkpoint kinase of the cell cycle pathway and is involved with the TP53 and BRCA1 pathways. CHEK2 is activated when there is a problem with the cell cycle. This results in the prevention of cellular entry into mitosis and thereby prevents cell replication. In patients who harbour germline mutations in CHEK2 the prevention of cell replication does not occur when required, thereby bypassing a critical checkpoint control mechanism [24].

Mutations in this gene have been associated with an increased risk of breast and bowel cancer development and currently efforts are underway to determine the precise relationship between CHEK2 and cancer risk in families that harbour both breast and colorectal cancer patients [25].

A known polymorphism has been identified in CHEK2 (1 100delC), which has already been linked to a hereditary breast and bowel cancer (HBBC) phenotype [25]. This mutation causes dysfunction of the kinase activity of the CHEK2 protein thereby losing a critical aspect of cell checkpoint control. The frequency of the known CHEK2 mutation is $1.1 \%$ in healthy individuals, $5.1 \%$ in breast cancer females with BRCA1 and BRCA2 mutations and $13.5 \%$ in male breast cancers. This data suggests that CHEK2 contributes to cancer risk but is not involved in disease initiation [24, 25].

\section{Conclusion}

The question "Does familial breast and bowel cancer exist?" cannot be unequivocally answered. Individuals that harbour germline mutations in MMR genes may be at increased risk of breast development but it is likely not to be reflected by a simple increase in disease incidence. More likely is the notion that individuals harbouring germline MMR gene mutations will have an accelerated disease process, which may be influenced by an interaction with modifier genes.

\section{References}

1. Evans DG, Cuzick J and Howell A. Cancer genetics clinics. Eur J Cancer 1996; 32A (3): 391-392.

2. Lynch HT, Riley BD, Weismann S, Coronel SM, Kinarsky Y, Lynch JF, Shaw TG and Rubinstein WS. Hereditary nonpolyposis colorectal carcinoma (HNPCC) and HNPCC-like families: Problems in diagnosis, surveillance, and management. Cancer 2004; 100 (1): 53-64.

3. Kaufman DJ, Beaty TH and Struewing JP. Segregation analysis of 231 Ashkenazi Jewish families for evidence of additional breast cancer susceptibility genes. Cancer Epidemiol Biomarkers Prev 2003; 12 (10): 1045-1052.

4. Muller A, Edmonston TB, Corao DA, Rose DG, Palazzo JP, Becker $\mathrm{H}$, Fry RD, Rueschoff $\mathrm{J}$ and Fishel R. Exclusion of breast cancer as an integral tumor of hereditary nonpolyposis colorectal cancer. Cancer Res 2002; 62 (4): 1014-1019.

5. Heisey RE, Carroll JC, Warner E, McCready DR and Goel V. Hereditary breast cancer. Identifying and managing BRCA1 and BRCA2 carriers. Can Fam Physician 1999; 45: 114-124. 
6. Watson P and Lynch HT. Extracolonic cancer in hereditary nonpolyposis colorectal cancer. Cancer 1993; 71 (3): 677-685.

7. Boyd J, Rhei E, Federici MG, Borgen PI, Watson P, Franklin B, Karr B, Lynch J, Lemon SJ and Lynch HT. Male breast cancer in the hereditary nonpolyposis colorectal cancer syndrome. Breast Cancer Res Treat 1999; 53 (1): 87-91.

8. de Leeuw WJ, van Puijenbroek M, Tollenaar RA, Cornelisse CJ, Vasen HF and Morreau H. Correspondence re: A. Muller et al, Exclusion of breast cancer as an integral tumor of hereditary nonpolyposis colorectal cancer. Cancer Res 2002; 62: 1014 1019. Cancer Res 2003; 63 (5): $1148-1149$.

9. Risinger JL, Barrett JL, Watson P, Lynch HT and Boyd J. Molecular genetic evidence of the occurrence of breast cancer as an integral tumor in patients with the hereditary nonpolyposis colorectal carcinoma syndrome. Cancer 1996; 77: 1836-1843.

10. Scott RJ, McPhillips M, Meldrum CJ, Fitzgerald PE, Adams K, Spigelman AD, du Sart D, Tucker K and Kirk J. Hereditary nonpolyposis colorectal cancer in 95 families: differences and similarities between mutation-positive and mutation-negative kindreds. Am J Hum Genet 2001; 68 (1): 118-127.

11. Borg A, Isola J, Chen J, Rubio C, Johansson U, Werelius B and Lindblom A. Germline BRCA1 and HMLH1 mutations in a family with male and female breast carcinoma. Int J Cancer 2000; 85 (6): 796-800.

12. Mitchell RJ, Farrington SM, Dunlop MG and Campbell H. Mismatch repair genes hMLH1 and hMSH2 and colorectal cancer: a HuGE review. Am J Epidemiol 2002; 156 (10): 885-902.

13. Caluseriu O, Cordisco EL, Viel A, Majore S, Nascimbeni R, Pucciarelli $S$ and Genuardi M. Four novel MSH2 and MLH1 frameshift mutations and occurrence of a breast cancer phenocopy in hereditary nonpolyposis colorectal cancer. Hum Mutat 2001; 17 (6): 521.

14. Thompson E, Meldrum C, Crooks R, McPhillips M, Thomas L, Spigelman A and Scott R. Hereditary non-polyposis colorectal cancer and the role of hPMS2 and hEXO1 mutations. Clin Genet 2004; 65 (3): 215-225.

15. Liu $Y$ and West SC. Distinct functions of BRCA1 and BRCA2 in double-strand break repair. Breast Cancer Res 2002; 4 (1): 9-13.

16. Bennett IC, Gattas M and Teh BT. The management of familial breast cancer. Breast 2000; 9 (5): 247-263.

17. Ford D, Easton DF, Stratton M, Narod S, Goldgar D, Devilee P, Bishop DT, Weber B, Lenoir G, Chang-Claude J, Sobol H, Teare MD, Struewing J, Arason A, Scherneck S, Peto J, Rebbeck TR, Tonin P, Neuhausen S, Barkardottir R, Eyfjord J, Lynch H, Ponder BA, Gayther SA, Birch JM, Lindblom A, Stoppa-Lyonnet D, Bignon Y, Borg A, Hamann U, Haites N, Scott RJ, Maugard CM, Vasen H, Seitz S, Cannon-Albright LA, Schofield A, Zelada-Hedman M, Breast Cancer Linkage Consortium. Genetic heterogeneity and penetrance analysis of the BRCA1 and BRCA2 genes in breast cancer families. The Breast Cancer Linkage Consortium. Am J Hum Genet 1998; 62 (3): 676-689.

18. Cancer risks in BRCA2 mutation carriers. The Breast Cancer Linkage Consortium. J Natl Cancer Inst 1999; 91 (15): 1310-1316.

19. Vasen HF, Morreau H and Nortier JW. Is breast cancer part of the tumor spectrum of hereditary nonpolyposis colorectal cancer? Am J Hum Genet 2001; 68 (6): 1533-1535.

20. Yee CJ, Roodi N, Verrier CS and Parl FF. Microsatellite instability and loss of heterozygosity in breast cancer. Cancer Res 1994; 54 (7): $1641-1644$.

21. Siah SP, Quinn DM, Bennett GD, Casey G, Flower RL, Suthers $G$ and Rudzki Z. Microsatellite instability markers in breast cancer: a review and study showing MSI was not detected at 'BAT 25' and 'BAT 26' microsatellite markers in early-onset breast cancer. Breast Cancer Res Treat 2000; 60 (2): 135-142.
22. Liu T, Wahlberg S, Burek E, Lindblom P, Rubio $C$ and Lindblom A. Microsatellite instability as a predictor of a mutation in a DNA mismatch repair gene in familial colorectal cancer. Gene Chromosome Canc 2000; 27 (1): 17-25.

23. Scully R and Puget N. BRCA1 and BRCA2 in hereditary breast cancer. Biochimie 2002; 84 (1): 95-102.

24. Meijers-Heijboer $H$, van den Ouweland A, Klijn J, Wasielewski M, de Snoo A, Oldenburg R, Hollestelle A, Houben M, Crepin $E$, van Veghel-Plandsoen M, Elstrodt F, van Duijn C, Bartels C, Meijers C, Schutte M, McGuffog L, Thompson D, Easton D, Sodha N, Seal S, Barfoot R, Mangion J, Chang-Claude J, Eccles D, Eeles R, Evans DG, Houlston R, Murday V, Narod S, Peretz T, Peto J, Phelan C, Zhang HX, Szabo C, Devilee P, Goldgar D, Futreal PA, Nathanson KL, Weber B, Rahman N and Stratton $M R$. Low-penetrance susceptibility to breast cancer due to CHEK2 $\left(^{*}\right) 1100$ delC in noncarriers of BRCA1 or BRCA2 mutations. Nat Genet 2002; 31 (1): 55-59.

25. Meijers-Heijboer $H$, Wijnen J, Vasen $H$, Wasielewski $M$, Wagner A, Hollestelle A, Elstrodt F, van den Bos R, de Snoo A, Fat GT, Brekelmans C, Jagmohan S, Franken P, Verkuijlen $P$, van den Ouweland A, Chapman P, Tops C, Moslein G, Burn J, Lynch H, Klijn J, Fodde R and Schutte M. The CHEK2 1100 delC mutation identifies families with a hereditary breast and colorectal cancer phenotype. Am J Hum Genet 2003; 72 (5): 1308-1314. 